\title{
Neurodevelopmental Outcome in Infants with Lower Urinary Tract Obstruction Based on Different Degrees of Severity
}

\author{
Sonia Monteiro ${ }^{a} \quad$ Ahmed A. Nassr $^{b}$ Peter S. Yun ${ }^{b}$ Robert Voigt ${ }^{a}$ \\ Chester J. Koh ${ }^{c}$ David R. Roth ${ }^{c}$ Michael Braun ${ }^{d}$ Joseph Angelo ${ }^{d}$ \\ Isabel Moscardo ${ }^{b}$ e $\quad$ Jimmy Espinoza ${ }^{b}$ Alireza A. Shamshirsaz ${ }^{b}$ \\ Michael Belfort $^{b}$ Rodrigo Ruano $^{f}$ Magdalena Sanz Cortes ${ }^{b}$
}

${ }^{a}$ Department of Developmental Pediatrics, Baylor College of Medicine, Houston, TX, USA; ${ }^{b}$ Department of Obstetrics and Gynecology, Baylor College of Medicine, Houston, TX, USA; 'Division of Urology, Department of Surgery, Texas Children's Hospital, and Scott Department of Urology, Baylor College of Medicine, Houston, TX,

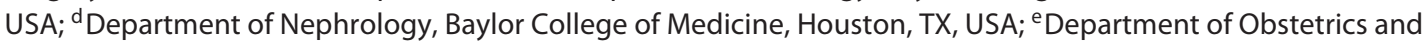
Gynecology, Hospital Clinic, Valencia, Spain; 'Department of Obstetrics and Gynecology, Mayo Clinic, Rochester, NY, USA

\begin{abstract}
Keywords
Congenital malformations · Developmental

outcomes · Fetal anomalies · Fetal surgery · Lower

urinary tract obstruction - Perinatal outcome
\end{abstract}

\begin{abstract}
Objective: To determine postnatal neurodevelopmental (ND) outcomes for children with congenital lower urinary tract obstruction (LUTO) based on disease severity. Methods: Twenty male infants with LUTO were classified prenatally as Stage 1 (normal amniotic fluid and renal function; $n=5$ ), Stage 2 (signs of obstruction with preserved renal function; $n=13$ ), and Stage 3 (signs of severe renal damage; $n=2)$. ND status was assessed using the Developmental Profile-3 test in 5 developmental domains (physical, adaptive behavior, social-emotional, cognitive, and communication). Each domain was considered to be delayed if standard scores were 2 or more SD below the mean. ND outcomes were compared between cases with an expected normal re-
\end{abstract}

nal function (LUTO Stage 1) and those with impaired renal function (LUTO Stages 2 and 3). Results from cases with Stage 2 were also compared to those from Stage 3. ORs were calculated to predict risk for adverse ND outcome for each domain considering prenatal and postnatal factors. Results: Gestational age (GA) at the diagnosis of LUTO was similar between both groups (Stage 1: $24.85 \pm 7.87$ vs. Stages 2 and $3: 21.4 \pm 4.31$ weeks; $p=0.24$ ). Twelve of 15 cases with Stage 2 or 3 underwent vesicoamniotic shunt placement compared to none of Stage 1 fetuses $(p<0.01)$. No differences in GA at delivery were detected between the groups (37.9 \pm 1.6 vs. $35.1 \pm 3.6$ weeks; $p=0.1$ ). One of the infants in the Stage 2 and 3 groups received a kidney transplant during followup. One case (20\%) from Stage 1 group required dialysis during the first 6 months of life, and 1 case from Stage 2 to 3 group required it during the first 6 months $(p=1.0)$, whereas 3 additional cases needed dialysis from 6 to 24 months ( $p=$ 0.6 ). Mean age at Developmental Profile 3 (DP-3) testing was $20.3 \pm 12.3$ months (Stage 1: $11.2 \pm 8.6$ vs. Stages 2 and 3: 23.4 \pm 13.4 months; $p=0.07)$. Fifteen of the 20 patients $(75 \%)$ had karger@karger.com

www.karger.com/fdt

Karger (c) 2020 S. Karger AG, Base

\footnotetext{
Magdalena Sanz Cortes, MD, PhD

Department of Obstetrics and Gynecology, Baylor College of Medicine Pavilion for Women, Texas Children's Hospital 6651 Fannin Street, Houston, TX (USA)

magdalec@bcm.edu
} 
no ND delays. Of the 5 patients with ND delays, 4 received dialysis. No differences in ND outcomes between infants with LUTO Stage 1 and those with Stages 2 and 3 were detected except for a trend toward better physical development in Stage 1 (102.6 \pm 11.6 vs. $80.7 \pm 34.9 ; p=0.05)$. Infants diagnosed with LUTO Stage 3 showed significantly lower adaptive scores than those diagnosed with Stage 2 (Stage 2: $101.9 \pm 22.3$ vs. Stage $3: 41.5 \pm 30.4 ; p=0.04$ ) and a nonsignificant trend for lower results in physical $(85.8 \pm 33.0 \mathrm{vs} .47 .5$ $\pm 38.9 ; p=0.1)$ and socio-emotional ( $94.7 \pm 17.9$ vs. $73.5 \pm$ $13.4 ; p=0.1$ ) domains. Infants who received dialysis showed 15 -fold increased risk ( $95 \% \mathrm{Cl} 0.89-251)$ for delayed socioemotional development $(p=0.06)$. Diagnosis of fetal renal failure increased the risk for delays in the adaptive domain 30 -fold (95\% Cl 1.29-93.1; $p=0.03)$. Infants with abnormal renal function had 19 times $(95 \% \mathrm{Cl} 1.95-292)$ increased risk for delays in the physical domain $(p=0.03)$. Conclusions: While most patients with LUTO do not exhibiting ND delays, our results support the importance of ND monitoring, especially in severe forms of LUTO, as increased severity of this condition may be associated with poorer ND outcomes.

(c) 2020 S. Karger AG, Basel

\section{Introduction}

Lower urinary tract obstruction (LUTO) occurs in 2.2 of every 10,000 births and is most commonly caused by posterior urethral valves [1]. It has high morbidity and mortality, with mortality rates reported between 33 and $75 \%$ in the perinatal period when untreated [2]. Typical ultrasound features of LUTO include marked distension of the bladder associated with hydroureteronephrosis [3]. While mild forms of the disease may lead to minimal clinical sequelae, the more severe forms commonly lead to oligohydramnios, a distended urinary tract, and renal dysplasia [3]. The loss of urinary flow into the amniotic space also leads to lung hypoplasia, and this may be a fatal complication [4]. Renal function is often significantly impaired, with some reports showing $>50 \%$ of LUTO patients having end-stage renal disease (ESRD) requiring dialysis soon after birth $[5,6]$, and $25-30 \%$ will require dialysis or renal transplant by the age of 5 years [7]. ESRD is a known risk factor for poor neurodevelopmental (ND) outcomes, with earlier onset during infancy associated with greater risk of impairment [8-12].

After the diagnosis of LUTO is made, the challenge becomes identifying which fetuses would benefit from intervention. Overall, it is accepted that those with normal karyotype, lack of other congenital anomalies, and pre- senting with oligohydramnios or anhydramnios and favorable urinary biochemistry would be considered good candidates [13]. Fetal intervention is predominantly aimed at restoration of amniotic fluid volume for prevention of pulmonary hypoplasia and urinary decompression for attenuation of ongoing renal damage [14-18]. Treatment options for this subset of fetuses include vesicoamniotic shunting (VAS) which is most commonly used, valve ablation via cystoscopy, and vesicostomy [3]. VAS is the most common antenatal treatment for LUTO. After this intervention, $91 \%$ of cases with severe forms of LUTO survived at 1 year of age [19] and survival increased when compared to expectant management (OR $2.53,95 \%$ CI 1.08-5.93) [17, 19].

Long-term follow-up in this population has been limited [6,19-22]. In a cohort study of 18 male children (mean age 5.8 years) treated prenatally with VAS, $78 \%$ of parents reported that their children had "normal development"; however, details regarding functioning within individual developmental domains, such as physical, adaptive, or cognitive functioning, were not reported, and a standardized measure of development was not used [19]. The assessment of ND outcomes in infants with LUTO considering different degrees of severity, has also not been reported to date. This information may be helpful for prenatal counseling of these patients. Thus, the primary aim of this study is to determine ND outcomes for children with congenital LUTO based on disease severity. As a secondary aim, we tried to identify prenatal and postnatal predictors that may be associated with an adverse ND outcome for this condition.

\section{Material and Methods}

This study was approved by the Institutional Review Board (H35770), and written consent was obtained from each participating mother. Patients with a prenatal diagnosis of LUTO who received perinatal management at our institution were considered eligible to participate in this study. Inclusion criteria were consenting pregnant women who had a singleton male fetus with an ultrasound diagnosis of LUTO established by the visualization of an enlarged bladder, bilateral hydroureters and hydronephrosis with or without cystic parenchymal renal disease $[23,24]$, no additional fetal structural anomalies, and normal chromosome testing.

\section{Diagnosis of LUTO Severity}

All patients referred to our institute with a prenatal diagnosis of LUTO were evaluated using the standardized multidisciplinary approach previously published by our group [25]. In summary, the patients underwent comprehensive obstetric ultrasound, fetal echocardiography, genetic consultation, and consultation with maternal fetal medicine, pediatric nephrology, and urology spe- 
Table 1. Prenatal LUTO classification

\begin{tabular}{llll}
\hline & $\begin{array}{l}\text { Stage I } \\
\text { (mild } \\
\text { LUTO) }\end{array}$ & $\begin{array}{l}\text { Stage II } \\
\text { (severe LUTO, with prenatal } \\
\text { findings suggestive of preserved } \\
\text { fetal renal function) }\end{array}$ & $\begin{array}{l}\text { Stage III } \\
\text { (severe LUTO, with prenatal } \\
\text { findings suggestive of fetal } \\
\text { abnormal renal function) }\end{array}$ \\
\hline Amount of amniotic fluid ( $>18$ weeks) & Normal & Oligohydramnios or anhydramnios & Oligohydramnios or anhydramnios \\
\hline Echogenicity of fetal kidneys & Normal & Hyperechogenic & Hyperechogenic \\
\hline Renal cortical cysts on ultrasound & Absent & Absent & Can be present \\
\hline Sonographic appearance of renal dysplasia & Absent & Absent & Can be present \\
\hline Fetal urinary biochemistry $(>18$ weeks) & Favorable & $\begin{array}{l}\text { Favorable within } 3 \text { consecutive } \\
\text { evaluations }\end{array}$ & $\begin{array}{l}\text { Not favorable after } 3 \text { consecutive } \\
\text { evaluations }\end{array}$ \\
\hline
\end{tabular}

LUTO classification as defined by Ruano et al. [25]. LUTO, lower urinary tract obstruction.

cialists. Only patients with a confirmed diagnosis of LUTO (megacystis, bilateral hydroureter, and hydronephrosis) with oligohydramnios/anhydramnios were offered vesicocentesis to assess the fetal urinary biochemistry and bladder refill. Also, genetic testing with amniocentesis or cordocentesis was offered to these patients. If the results of the initial fetal bladder tap were unfavorable, a second vesicocentesis was offered to allow for evaluation of a fresh urine sample. This procedure was repeated for a third time in select cases.

Fetal renal function was evaluated using a combination of fetal renal ultrasound parameters and urinary biochemical markers [26]. Patients were staged according to our published Prenatal Classification of LUTO Severity [25] (Table 1) considering the amount of amniotic fluid, urinary biochemistry, and presence of renal cysts or signs of renal dysplasia. VAS placement was offered to patients with evidence of significant obstruction and favorable fetal renal function parameters (Stage 2 LUTO, $n=13$ ). Further details on VAS placement are included in the online supplementary Materials (for all online suppl. material, see www.karger.com/ doi/10.1159/000504977. Following shunt placement, weekly ultrasounds were performed, and repeat placement was offered if the shunt was obstructed or dislodged. The number of shunts that are placed during the entire pregnancy and gestational age (GA) at placement were recorded. Those patients with Stage 1 LUTO, defined as normal amniotic fluid level and normal fetal renal functioning $(n=5)$, were treated expectantly with weekly ultrasound follow-up. Patients with Stage $3(n=2)$ were not considered as candidates for VAS placement and were followed on a weekly basis as well [26-29]. Fetal renal failure was diagnosed by the presence of ultrasonographic signs suggestive of renal dysplasia: hyperechogenic kidneys with renal cortical cysts and absence of cortico-medullary differentiation, in addition to the presence of nondilated or mildly dilated thick wall fetal urinary bladder with progressively decreasing amount of amniotic fluid if detected at any time during the course of the pregnancy. One of the parameters that was recorded at each follow-up ultrasound scan was the amniotic fluid index, where indices $<5 \mathrm{~cm}$ was considered as severe oligohydramnios. Postnatal renal function was defined for the purpose of this study as abnormal if at 6 months of age creatine was $\geq 0.5 \mathrm{mg} / \mathrm{dL}$ [26].

Delivery timing and route were based on standard obstetric principles. After delivery, all surviving infants were evaluated and followed by pediatric specialists, including pediatric urologists, nephrologists, and neonatologists. A voiding cystourethrogram and postnatal cystoscopy were performed to evaluate the bladder and the urethra in all cases. Postnatal renal function, the requirement of dialysis, and the need for renal transplant were also recorded.

\section{ND Assessment}

The mothers of surviving infants with prenatally diagnosed LUTO were interviewed by a Developmental Behavioral Pediatrician using a standardized child development assessment instrument, the DP-3 [30, 31]. The DP-3 includes 180 items, each describing a particular ND skill. The respondent indicates whether or not the child has mastered the skill in question. Standard scores are obtained for overall general development as well as for the following 5 ND scales: Physical (assessment of large and small muscle coordination, strength, stamina, flexibility, and sequential motor skills), adaptive behavior (ability to cope independently with the environment- to eat, dress, work, take care of self, and others), social-emotional (interpersonal skills, social/emotional understanding, functioning in social situations, manner in which child relates to peers, and adults), cognitive (intellectual abilities and skills prerequisite to academic achievement), and communication (expressive and receptive communication skills, including written, spoken, and gestural language) [30,31]. Additionally, the combination of the scores obtained from these 5 developmental domains was used to calculate a general development standard score (GDS), which represents the overall development in each child. For those patients whose standard score in an individual ND domain was $<50$, a developmental quotient was calculated (by dividing the infant's developmental age equivalent determined by the DP-3 by their chronological age and multiplying by 100), and these developmental quotients were used in place of standard scores for these patients. This was done for 3 of the 20 patients and included 3 
Table 2. Maternal characteristics

\begin{tabular}{lccc}
\hline & $\begin{array}{l}\text { LUTO Stage 1 } \\
(n=5)\end{array}$ & $\begin{array}{l}\text { LUTO Stages 2 } \\
\text { and 3 }(n=15)\end{array}$ & p value \\
\hline $\begin{array}{lccc}\text { Maternal age, years } \\
\text { Race }\end{array}$ & $\begin{array}{c}26.83 \pm 7.93 \\
\quad \text { White }\end{array}$ & $26.94 \pm 4.69$ & 0.96 \\
$\quad$ Afro-American & & $10(66.7)$ & 0.32 \\
$\quad$ Asian & $2(40)$ & $4(26.7)$ & \\
$\quad$ Hispanic ethnicity & $1(6.7)$ & 0.07 \\
Maternal BMI at enrolment, $\mathrm{kg} / \mathrm{m}^{2}$ & $27.51 \pm 4.3$ & $29.83 \pm 8.24$ & 0.45 \\
$\quad$ Primiparous & $3(60)$ & $3(20)$ & 0.13 \\
\hline
\end{tabular}

Results are expressed as mean \pm SD and number of cases (percentages) when appropriate. $p$ represents the comparison between both groups. Quantitative data were compared using $t$ test for independent groups and quantitative data were compared using chi-square or Fisher's tests.

LUTO, lower urinary tract obstruction; BMI, body mass index.

Table 3. Perinatal characteristics

\begin{tabular}{lccc}
\hline & $\begin{array}{l}\text { LUTO Stage 1 } \\
(n=5)\end{array}$ & $\begin{array}{l}\text { LUTO Stages 2 } \\
\text { and 3 }(n=15)\end{array}$ & $p$ value \\
\hline GA at delivery, weeks & $37.9 \pm 1.62$ & $35.12 \pm 3.63$ & 0.12 \\
Delivery <32 weeks of GA & 0 & $3 / 15(20)$ & 0.54 \\
Delivery <37 weeks of GA & $1 / 5(20)$ & $8 / 15(53.3)$ & 0.32 \\
Newborn weight, g $_{\text {Newborn weight percentile }}^{1}$ & $3,353.40 \pm 581.58$ & $2,767.86 \pm 796.59$ & 0.15 \\
Newborn height, cm $_{\text {Newborn height percentile }}{ }^{1}$ & $43.43 \pm 32$ & $44.35 \pm 31.13$ & 0.95 \\
Head circumference, cm $^{\text {Head circumference percentile }}{ }^{1}$ & $50.34 \pm 1.95$ & $46.41 \pm 4.62$ & 0.09 \\
\hline
\end{tabular}

${ }^{1}$ WHO Multicentre Growth Reference Study Group. WHO Child Growth Standards: Length/height-for-age, weight-for-age, weight-for-length, weight-for-height, and body mass index-for-age: Methods and development. Geneva: World Health Organization, 2006.

$p$ : Results are expressed as mean $\pm \mathrm{SD}$ or ratios and percentages. Comparisons between both groups were carried out by $t$ test for independent samples for quantitative data. Chisquare or Fisher test was performed to compare qualitative data.

LUTO, lower urinary tract obstruction; GA, gestational age.

physical and 2 adaptive developmental quotients. Standard scores were interpreted as delayed if they were 2 or more SD below the mean (standard score $\leq 70$ ) or not delayed (standard score $>70$ ). The proportion of cases in each LUTO stage with a delayed neurodevelopment domain or GDS was calculated.

\section{Statistical Analyses}

Student $t$ test for independent samples and Pearson's $\chi^{2}$ or Fisher's exact tests were used to compare quantitative and qualitative data, respectively. Comparisons of ND outcomes were performed by comparing cases with the diagnosis of LUTO with expected normal renal function before birth (Stage 1) versus those with ex- spected abnormal renal function (Stages 2 and 3). Results from DP-3 test between infants from Stage 2 to 3 were also compared. ORs of having an abnormal ND outcome (delayed GDS $[\leq 70]$, or developmental delay in each developmental domain [standard score $\leq 70]$ ), were calculated using GA at delivery $<37$ weeks, fetal intervention (VAS placement), fetal renal failure, postnatal renal function, severe oligohydramnios, LUTO Stage 2, LUTO Stage 3, need for dialysis and renal transplant as independent variables on a binary logistic regression. Results were considered significant at a $p$ value $<0.05$. All statistical calculations were done using SPSS statistical software version 17.0 (SPSS for windows, SPSS Inc., Chicago, IL, USA). 
Table 4. Renal function

\begin{tabular}{|c|c|c|c|}
\hline & $\begin{array}{l}\text { LUTO Stage } 1 \\
(n=5), n(\%)\end{array}$ & $\begin{array}{l}\text { LUTO Stages } 2 \text { and } 3 \\
(n=15), n(\%)\end{array}$ & $p$ value \\
\hline GA at the diagnosis of LUTO, weeks & $24.85 \pm 7.87$ & $21.4 \pm 4.31$ & 0.24 \\
\hline \multicolumn{4}{|l|}{ Severe oligohydramnios detected during the } \\
\hline pregnancy ${ }^{1}$ & 0 & $10(66.7)$ & 0.06 \\
\hline Fetal renal failure ${ }^{2}$ & $1(20)$ & $2(13.3)$ & 1.0 \\
\hline Proportion of cases in which a VAS was placed & 0 & $12(80)$ & $<0.01$ \\
\hline Cases who received 1 shunt & - & $7 / 12(58.33)$ & - \\
\hline Cases who received 2 shunts & - & $3 / 12(25)$ & - \\
\hline Cases who received $>2$ shunts & - & $2 / 12(16.67)$ & - \\
\hline GA at first shunt placement, weeks & - & $22.62 \pm 5.58$ & - \\
\hline Postnatal diagnosis & & & 0.06 \\
\hline Posterior urethral valves & $3(60)$ & $12(80)$ & \\
\hline Urethral atresia & 0 & $2(13.3)$ & \\
\hline PBS & 0 & $1(6.7)$ & \\
\hline Reflux & $2(40)$ & 0 & \\
\hline Postnatal surgery & $3(60)$ & $10(66.7)$ & 1.0 \\
\hline Postnatal renal function & & & 0.72 \\
\hline Normal & $3(75)$ & $9(60)$ & \\
\hline Abnormal & $1(25)$ & $6(40)$ & \\
\hline Kidney transplant during follow-up & 0 & $1(6.7)$ & 1.0 \\
\hline Need for dialysis at $\leq 6$ months & $1(20)$ & $1(6.7)$ & 1.0 \\
\hline Age at initiation of dialysis, days & 15 & 4 & 0.44 \\
\hline Need for dialysis until 2 years of life & $1(20)$ & $4(26.7)$ & 1.0 \\
\hline
\end{tabular}

\footnotetext{
${ }^{1}$ Oligohydramnios defined as AFI $<5 \mathrm{~cm}$.

${ }^{2}$ Fetal renal failure was diagnosed by the presence of ultrasonographic signs suggestive of renal dysplasia: hyperechogenic kidneys with renal cortical cysts and absence of cortico-medullary differentiation, in addition to the presence of nondilated or mildly dilated thick wall fetal urinary bladder with progressively decreasing amount of amniotic fluid.

Results are expressed as mean \pm SD or ratios and percentages. Comparisons between both groups were carried out by $t$ test for independent samples for quantitative data. Chi square or Fisher test was performed to compare qualitative data.
}

LUTO, lower urinary tract obstruction; GA, gestational age; VAS, vesicoamniotic shunt; PBS, prune Belly syndrome.

\section{Results}

\section{Prenatal Renal Study}

Twenty-four patients were enrolled in this study, but ND assessment could only be performed on 20 patients, as 4 patients were lost to follow-up postnatally. Five cases were classified as Stage 1, 13 cases were classified as Stage 2 , and 2 cases as were classified as Stage 3. Twelve patients underwent VAS placement, and 8 did not. All of the patients that had undergone a fetal intervention were classified as LUTO Stage 2. Patients that did not undergo fetal intervention were classified as LUTO Stage 1 in 5 cases, Stage 2 in 1 case, and Stage 3 in 2 cases. Fetal intervention cases required 1 shunt placement in 8 cases,
2 shunt placements and 5 interventions in 1 case, and 3 interventions were needed in 2 cases. Mean GA at first intervention was $22.6 \pm 5.6$ weeks, and in cases where multiple shunt placements were necessary, the latest shunt placement was performed at 31.1 weeks. No differences in maternal body mass index or other maternal characteristics were detected between groups (Table 2).

Perinatal characteristics between groups were similar (Table 3). No significant differences in GA at delivery, rate of preterm delivery, or delivery at $<32$ weeks were detected. More than half of the cases from Stage 2 to 3 were delivered at $<37$ weeks (53.3\%) and $20 \%$ were delivered at $<32$ weeks. The latter were cases diagnosed as Stage 2 , which is related to the $18.8 \%$ rate of PPROM that 
Table 5. ND assessment results

\begin{tabular}{lcccc}
\hline & $\begin{array}{l}\text { All LUTO } \\
\text { patients }(n=20)\end{array}$ & $\begin{array}{l}\text { LUTO Stage 1 } \\
(n=5)\end{array}$ & $\begin{array}{l}\text { LUTO Stages 2 } \\
\text { and 3 }(n=15)\end{array}$ & $p$ value* \\
\hline Age at test, months & $20.35 \pm 12.34$ & $11.2 \pm 8.58$ & $23.4 \pm 13.43$ & 0.07 \\
General development & $98.94 \pm 17.3$ & $99.2 \pm 7.72$ & $98.83 \pm 20.34$ & 0.97 \\
Delayed general development & $2 / 17(11.8)$ & 0 & $2 / 12(16.7)$ & 1.0 \\
Physical development & $83.15 \pm 38.75$ & $102.6 \pm 11.63$ & $80.73 \pm 34.95$ & 0.05 \\
Delayed physical development & $4 / 20(20)$ & 0 & $4 / 15(26.7)$ & 0.53 \\
Adaptative development & $94.7 \pm 29.82$ & $101.2 \pm 3.56$ & $93.87 \pm 30.75$ & 0.38 \\
Delayed adaptative development & $3 / 20(15)$ & 0 & $3 / 15(20)$ & 0.53 \\
Social-emotional development & $93.1 \pm 16.56$ & $96.6 \pm 8.73$ & $91.93 \pm 18.56$ & 0.59 \\
Delayed social-emotional development & $3 / 20(15)$ & 0 & $3 / 15(20)$ & 0.53 \\
Cognitive development & $93.65 \pm 15.25$ & $97.4 \pm 14.71$ & $92.4 \pm 15.72$ & 0.54 \\
Delayed cognitive development & $1 / 20(5)$ & 0 & $1 / 15(6.7)$ & 1.0 \\
Communication & $99.3 \pm 13.28$ & $98.4 \pm 8.79$ & $99.6 \pm 14.72$ & 0.86 \\
Delayed communication development & $1 / 20(5)$ & 0 & $1 / 15(6.7)$ & 1.0 \\
Number of cases with $\geq 1$ delayed domains & $5(25)$ & 0 & $5(33.3)$ & 0.26 \\
\hline
\end{tabular}

Delayed development was determined if standard score was $<2 \mathrm{SD}$, so if $\leq 70$. $^{*} p<0.05$.

Results are expressed as mean \pm SD or ratios and percentages. Comparisons between both groups were carried out by $t$ test for independent samples for quantitative data. Chi-square or Fisher test were performed to compare qualitative data.

ND, neurodevelopmental; LUTO, lower urinary tract obstruction.

occurred at $<32$ weeks for all patients. Also, newborn characteristics (Table 3), including birth weight, neonatal length, and head circumference, were comparable between both groups.

The diagnosis of oligohydramnios was made at a later GA in the cases diagnosed with Stage 1 than in those with Stage 2 and 3 (Table 4). At the time of developmental assessment, none of the Stage 1 and $13 \%$ of the Stage 2 and 3 infants required a renal transplant. Dialysis was necessary in one of the Stage 1 infants (20\%) and 4 of the Stage 2 and 3 infants (26.7\%) during the first 2 years of life.

\section{ND Assessment}

The mean patient age at the time of ND assessment was $20.35 \pm 12.3$ months, with a mean GA at delivery of $36 \pm 2.5$ weeks. On the DP-3, 15 of the 20 patients (75\%) with LUTO did not evidence a delay in any ND domain. Of these 15 patients, $80 \%(n=12)$ had a GDS in the average range (standard score $>84$ ), and $20 \%$ had a GDS in the above average range (standard score $>115$ ). Considering the entire cohort of LUTO infants, the proportion of cases that showed delays in different developmental scales ranged from $5 \%$ in the communication and cognitive domains to $20 \%$ in the physical development domain (Table 5).
None of the patients with Stage 1 LUTO exhibited ND delays. Of the patients with Stage 2 LUTO, 23\% (3 of 13) had a delay in one or more ND domain. Both patients with Stage 3 LUTO (significant renal impairment without fetal intervention) were found to be developmentally delayed. When ND outcomes were compared between infants diagnosed as Stage 2 vs. 3, lower scores were detected in the latter, with significantly lower scores in adaptive domain (Stage $2101.92 \pm 22.32$ vs. Stage $341.5 \pm 30.41 ; p<0.01)$ and a trend toward lower scores in social-emotional (Stage $294.77 \pm 17.93$ vs. Stage $373.5 \pm 13.43 ; p=0.13$ ) and physical domains (Stage $285.85 \pm 32.96$ vs. Stage $3: 47.5 \pm 38.89 ; p=0.15$ ). There was a higher proportion of cases with abnormal general development ( 0 vs. $66.7 \% . p=0.02$ ), physical development ( 6.7 vs. $60 \% ; p=0.03)$, adaptive development ( 0 vs. $60 \% ; p<0.01)$, and socio-emotional development ( 0 vs. $60 \% ; p<0.01)$ in those who received dialysis $(n=5)$ compared to those that did not $(n=15)$. Online supplementary Table 1 Overall, there was a trend toward lower scores in all domains from the group of infants undergoing dialysis when compared to those that did not receive it. Online supplementary Table 1, reaching statistical significance in physical, adaptive, and socialemotional domains. 
Of the 5 patients (25\%) who evidenced ND delays, 3 exhibited delays in $>1$ ND domain, and all of them had received dialysis. Delays in physical development were the most common delays (4 out of 5 patients).

The odds of delayed physical development were 19.5 times higher (95\% CI 1.29-292.1; $p=0.03$ ) with the diagnosis of postnatal abnormal renal function, 3 times higher with severe oligohydramnios (95\% CI 0.24-36.32; $p=$ 0.38 ), and 7 times higher in patients who eventually required dialysis (95\% CI $0.6-81.68 ; p=0.12$ ). Patients on dialysis had 14 times the odds of delayed general development $(95 \%$ CI $0.45-434.1 ; p=0.13)$ and 15 times the odds of having delayed social emotional development (95\% CI $0.89-251.05 ; p=0.06)$.

With regard to survival rates at 2 years of age, at the time of this assessment, 10 patients were $<2$ years of age. At the time of submission, 8 of these patients had survived past 2 years of age and 2 were lost to follow-up.

\section{Discussion}

Although LUTO is one of the most severe congenital diseases that can be diagnosed during fetal life, and severe LUTO is usually associated with high perinatal mortality and morbidity resulting from pulmonary hypoplasia and ESRD [7], we found that a majority of patients with LUTO did not exhibit ND delays. We found that the presence of developmental delays increased with the severity of LUTO and that neurodevelopment was most impaired for those patients requiring dialysis. We also found that for those LUTO patients with more impaired renal functioning, physical and adaptive development were more negatively impacted than cognitive or communication development.

Some investigators have advocated for utilizing fetal urinalysis for fetal triage and the allocation of risk of postnatal renal damage prospectively $[15,32]$. Other authors have advocated that overall diagnostic accuracy of such testing is low and may be unreliable when deciding on treatment [33]. Although we found that renal functioning at birth was abnormal for LUTO patients compared to the general population, we found no differences in renal functioning at birth between Stage 1 and 2 LUTO patients.

The assessment of severity of renal disease in fetal life using ultrasound and urinary indices has shown a correlation with renal function postnatally. The classification of fetal renal function using the Texas Children's severity staging is a useful tool to evaluate patients who are considered candidates for fetal intervention and to counsel families to establish their expectations for postnatal outcomes. Nevertheless, there is a significant gap in knowledge of the expectations that families may have regarding the ND outcomes that may be expected in this population. Previous studies have been limited to informal assessments without the use of standardized developmental measures. Additionally, patterns of developmental delay across individual domains of development have not previously been reported in this population [19].

We observed that the majority of infants with LUTO had normal ND outcomes. This is consistent with previously published reports that have shown that children with mild to moderate renal disease have IQ, academic achievement, and attention/executive functioning that fall within age appropriate expectations [34]. The prevalence of parent-reported ND disorders is $15 \%$ for all children and 9\% for children between 2 and 3 years of age, while based on direct developmental assessment, $13 \%$ of children at 9 and 24 months have been reported to have delays in their development $[35,36]$. Although the overall rate of developmental delay in our cohort of LUTO cases was higher (25\%), when broken down by individual developmental domain, only $10 \%$ ( 2 of 20 ) patients showed delays in cognitive and/or language domains.

Our findings are consistent with previous studies that have shown the need for dialysis during infancy has a negative impact on neurodevelopment [37]. In a study of 21 patients who required dialysis prior to 24 months of age, $71 \%$ had evidence of ND impairment based on neuropsychological testing and evaluation with multiple specialists, including a neurologist, physiotherapist, and occupational therapist [37]. In addition, children with ESRD diagnosed during infancy have been shown to have lower cognitive functioning, lower academic achievement, and deficits in executive functioning when compared to sibling controls [8]. Further, adults with a history of ESRD during childhood have been shown to have lower educational achievement, an increased rate of unemployment, and a lower likelihood to live independently [38]. Chronic kidney disease has been correlated with impaired attention regulation and inhibitory control in pediatric patients from 6 to 21 years of age, which directly impacts learning as well as functioning at home and in the community [39].

In our cohort, patients with more impaired renal function had increased risk for physical and adaptive impairments. Given these results, therapeutic interventions 
(such as physical and occupational therapy) for this population should be considered at an early age to address these deficits to maximize long-term outcomes. The benefits of early intervention programs, as mandated by Part $\mathrm{C}$ of the Individuals with Disabilities Education Act, are well established, as $71 \%$ of all early intervention participants at $<3$ years of age show greater than expected growth in knowledge and skills, and 52\% of these participants exit early intervention programs with development within age appropriate limits [40].

It has been hypothesized that the uremia and anemia associated with chronic kidney disease may alter metabolism in the brain and impact both neuronal myelination and synaptic development [41]. If such altered neuronal metabolism occurs during infancy and early development, it could be further hypothesized that the effect on ND outcomes would be more significant.

A strength of this study is that it is the first study to report ND outcomes using a standardized developmental assessment measure in children with LUTO. In previous studies based on informal parent report of "normal" or "abnormal" development (without the use of a standardized developmental measure), additional information regarding differences within specific domains of development have not been able to be reported. Furthermore, our study provides evidence regarding the pre- and postnatal variables that are most predictive of ND impairments in specific ND domains using a standardized developmental assessment measure.

Limitations of our study include its small sample size. However, our sample size is similar in size to studies reporting outcomes in children with ESRD $[8,9]$. ND assessment in our study was completed with a standardized measure based on parent interview; however, direct clinical confirmation was not performed. Despite this limitation, it has been previously shown that parental reporting of both language and motor abilities in children with and without ND disabilities is comparable to and not significantly different from direct assessment $[42,43]$. Although our study accounted for many pre- and postnatal variables, we did not account for additional factors, including comorbid medical conditions, sociodemographic differences, and psychosocial risk factors that can influence neurodevelopment in the first few years of life [44]. Additionally, although maternal and perinatal characteristics did not vary among groups, the average age for ND assessment for infants with Stage 1 LUTO was lower than that for infants with Stages 2 and 3 LUTO (11 vs. 23 months); however, this was not a significant difference $(p=0.07)$. Finally, more severe developmental delays will present during infancy, while milder ND delays may present when children are older. Thus, our patients undergoing assessment at a younger age should have close ND monitoring over time.

\section{Conclusions}

A majority of infants in our study with LUTO are not exhibiting ND delays. Rates of delayed development do not significantly differ between those who underwent fetal intervention and those who did not. Increased rates of delay in physical and adaptive development are seen with increased severity of LUTO and are higher than reported in the general population. Based on our results, infants receiving dialysis can be identified as one of the groups of LUTO infants with a high risk for ND delays. These findings support the need for ongoing longitudinal ND follow-up of all LUTO patients, regardless of severity or history of fetal intervention, to monitor ND outcomes.

\section{Acknowledgment}

We have no acknowledgments.

\section{Statement of Ethics}

This study was approved by the Baylor College of Medicine Institutional Review Board with all mothers providing written informed consent.

\section{Disclosure Statement}

The authors have no conflicts of interest to declare.

\section{Funding Sources}

There was no funding for this study.

\section{Author Contributions}

Dr. Sonia Monteiro conceptualized and designed the study, collected data, drafted the initial manuscript, and reviewed and revised the manuscript. Dr. Magdalena Sanz Cortes conceptualized the study, conducted statistical analyses and interpretation, collected data contributed to drafting the initial manuscript, and reviewed and revised the manuscript. Dr. Rodrigo Ruano con- 
ceptualized and designed the study, participated in data gathering, data analysis and interpretation of the results, and reviewed and revised the manuscript. Dr. Robert Voigt assisted in the conceptualization and design of the study. He reviewed and revised the manuscript. Dr. Peter S. Yun was involved in data gathering, analysis and interpretation of the results of the analysis. He reviewed and revised the manuscript. Dr. Ahmed A. Nassr par- ticipated in data gathering, was involved in analysis and interpretation of results, and reviewed and revised the manuscript. Drs. Chester J. Koh, David R. Roth, Michael Braun, Joseph Angelo, Isabel Moscardo, Jimmy Espinoza, Alireza A. Shamshirsaz, and Michael Belfort contributed to the clinical care of these patients, interpretation of the results, and review of the manuscript.

\section{References}

1 Ruano R, Safdar A, Au J, Koh CJ, Gargollo P, Shamshirsaz AA, et al. Defining and predicting 'intrauterine fetal renal failure' in congenital lower urinary tract obstruction. Pediatr Nephrol. 2016 Apr;31(4):605-12.

2 Morris RK, Malin GL, Quinlan-Jones E, Middleton LJ, Hemming K, Burke D, et al.; Percutaneous vesicoamniotic shunting in Lower Urinary Tract Obstruction (PLUTO) Collaborative Group. Percutaneous vesicoamniotic shunting versus conservative management for fetal lower urinary tract obstruction (PLUTO): a randomised trial. Lancet. 2013 Nov 382(9903):1496-506.

3 Haeri S. Fetal Lower Urinary Tract Obstruction (LUTO): a practical review for providers. Matern Health Neonatol Perinatol. 2015 Nov; $1(1): 26$.

4 Kilbride HW, Yeast J, Thibeault DW. Defining limits of survival: lethal pulmonary hypoplasia after midtrimester premature rupture of membranes. Am J Obstet Gynecol. 1996 Sep;175(3 Pt 1):675-81.

5 Morris RK, Kilby MD. Long-term renal and neurodevelopmental outcome in infants with LUTO, with and without fetal intervention. Early Hum Dev. 2011 Sep;87(9):607-10.

6 Freedman AL, Johnson MP, Smith CA, Gonzalez R, Evans MI. Long-term outcome in children after antenatal intervention for obstructive uropathies. Lancet. 1999 Jul; 354(9176):374-7.

7 Nassr AA, Shazly SA, Abdelmagied AM, Araujo Júnior E, Tonni G, Kilby MD, et al. Effectiveness of vesicoamniotic shunt in fetuses with congenital lower urinary tract obstruction: an updated systematic review and metaanalysis. Ultrasound Obstet Gynecol. 2017 Jun;49(6):696-703.

8 Johnson RJ, Warady BA. Long-term neurocognitive outcomes of patients with end-stage renal disease during infancy. Pediatr Nephrol. 2013 Aug;28(8):1283-91.

9 Moser JJ, Veale PM, McAllister DL, Archer DP. A systematic review and quantitative analysis of neurocognitive outcomes in children with four chronic illnesses. Paediatr Anaesth. 2013 Nov;23(11):1084-96.

10 Hadzimuratovic E, Skrablin S, Hadzimuratovic A, Dinarevic SM. Postasphyxial renal injury in newborns as a prognostic factor of neurological outcome. J Matern Fetal Neonatal Med. 2014 Mar;27(4):407-10
11 Gerson AC, Butler R, Moxey-Mims M, Wentz A, Shinnar S, Lande MB, et al. Neurocognitive outcomes in children with chronic kidney disease: current findings and contemporary endeavors. Ment Retard Dev Disabil Res Rev. 2006;12(3):208-15.

12 Amr M, El-Gilany AH, Bakr A, El Sheshtawy E. Assessing the intelligence of children with chronic kidney diseases. Saudi J Kidney Dis Transpl. 2013 Jan;24(1):67-71.

13 Ruano R. Fetal surgery for severe lower urinary tract obstruction. Prenat Diagn. 2011 Jul 31(7):667-74

14 Spaggiari E, Dreux S, Czerkiewicz I, Favre R, Schmitz T, Guimiot F, et al. Fetal obstructive uropathy complicated by urinary ascites: outcome and prognostic value of fetal serum $\beta-2$ microglobulin. Ultrasound Obstet Gynecol. 2013 Feb;41(2):185-9.

15 Johnson MP, Bukowski TP, Reitleman C, Isada NB, Pryde PG, Evans MI. In utero surgical treatment of fetal obstructive uropathy: a new comprehensive approach to identify appropriate candidates for vesicoamniotic shunt therapy. Am J Obstet Gynecol. 1994 Jun; 170(6):1770-6.

16 Manning FA, Harrison MR, Rodeck C. Catheter shunts for fetal hydronephrosis and hydrocephalus. Report of the International Fetal Surgery Registry. N Engl J Med. 1986 Jul; 315(5):336-40.

17 Elder JS, Duckett JW Jr, Snyder HM. Intervention for fetal obstructive uropathy: has it been effective? Lancet. 1987 Oct;2(8566): 1007-10.

18 Crombleholme TM, Harrison MR, Golbus MS, Longaker MT, Langer JC, Callen PW, et al. Fetal intervention in obstructive uropathy: prognostic indicators and efficacy of intervention. Am J Obstet Gynecol. 1990 May; 162(5):1239-44.

19 Biard JM, Johnson MP, Carr MC, Wilson RD, Hedrick HL, Pavlock C, et al. Long-term outcomes in children treated by prenatal vesicoamniotic shunting for lower urinary tract obstruction. Obstet Gynecol. 2005 Sep; 106(3):503-8.

20 Makino Y, Kobayashi H, Kyono K, Oshima K, Kawarabayashi T. Clinical results of fetal obstructive uropathy treated by vesicoamniotic shunting. Urology. 2000 Jan;55(1):118-22.

21 McLorie G, Farhat W, Khoury A, Geary D, Ryan G. Outcome analysis of vesicoamniotic shunting in a comprehensive population. J Urol. 2001 Sep;166(3):1036-40.
22 Holmes N, Harrison MR, Baskin LS. Fetal surgery for posterior urethral valves: longterm postnatal outcomes. Pediatrics. $2001 \mathrm{Jul}$; 108(1):E7.

23 Kaefer M, Peters CA, Retik AB, Benacerraf $B B$. Increased renal echogenicity: a sonographic sign for differentiating between obstructive and nonobstructive etiologies of in utero bladder distension. J Urol. 1997 Sep; 158(3 Pt 2):1026-9.

24 Malin G, Tonks AM, Morris RK, Gardosi J, Kilby MD. Congenital lower urinary tract obstruction: a population-based epidemiological study. BJOG. 2012 Nov;119(12):1455-64.

25 Ruano R, Sananes N, Wilson C, Au J, Koh CJ, Gargollo P, et al. Fetal lower urinary tract obstruction: proposal for standardized multidisciplinary prenatal management based on disease severity. Ultrasound Obstet Gynecol. 2016 Oct;48(4):476-82.

26 Nassr AA, Koh CK, Shamshirsaz AA, Espinoza J, Sangi-Haghpeykar H, Sharhan D, et al. Are ultrasound renal aspects associated with urinary biochemistry in fetuses with lower urinary tract obstruction? Prenat Diagn. 2016 Dec;36(13):1206-10.

27 Blaicher W, Häusler M, Gembruch U, Bollmann R, Terinde R, Rempen A, et al. Fetoamniotic shunting - experience of six centres. Ultraschall Med. 2005 Apr;26(2):134-41.

28 Agarwal SK, Fisk NM. In utero therapy for lower urinary tract obstruction. Prenat Diagn. 2001 Nov;21(11):970-6.

29 Brown C, Morris RK, Daniels J, Khan KS, Lilford RJ, Kilby MD. Effectiveness of percutaneous vesico-amniotic shunting in congenital lower urinary tract obstruction: divergence in prior beliefs among specialist groups. Eur J Obstet Gynecol Reprod Biol. 2010 Sep;152(1): 25-9.

30 Alpern D, Boll TJ, Shearer M. Developmental Profile-II. Aspen (CO): Psychological Development Publications; 1986.

31 Glascoe FP, Byrne KE. The usefulness of the Developmental Profile-II in developmental screening. Clin Pediatr (Phila). 1993 Apr; 32(4):203-8

32 Freedman AL, Bukowski TP, Smith CA, Evans MI, Berry SM, Gonzalez R, et al. Use of urinary beta-2-microglobulin to predict severe renal damage in fetal obstructive uropathy. Fetal Diagn Ther. 1997 Jan-Feb;12(1):16. 
33 Morris RK, Quinlan-Jones E, Kilby MD, Khan KS. Systematic review of accuracy of fetal urine analysis to predict poor postnatal renal function in cases of congenital urinary tract obstruction. Prenat Diagn. 2007 Oct; 27(10):900-11.

34 Hooper SR, Gerson AC, Butler RW, Gipson DS, Mendley SR, Lande MB, et al. Neurocognitive functioning of children and adolescents with mild-to-moderate chronic kidney disease. Clin J Am Soc Nephrol. 2011 Aug;6(8):1824-30.

35 Bitsko RH, Holbrook JR, Robinson LR, Kaminski JW, Ghandour R, Smith C, et al.; EdS. Health Care, Family, and Community Factors Associated with Mental, Behavioral, and Developmental Disorders in Early Childhood United States, 2011-2012. MMWR Morb Mortal Wkly Rep. 2016 Mar;65(9):221-6.

36 Rosenberg SA, Zhang D, Robinson CC. Prevalence of developmental delays and participation in early intervention services for young children. Pediatrics. 2008 Jun;121(6):e15039.

37 Laakkonen $\mathrm{H}$, Lönnqvist $\mathrm{T}$, Valanne L, Karikoski J, Holmberg C, Rönnholm K. Neurological development in 21 children on peritoneal dialysis in infancy. Pediatr Nephrol. 2011 Oct;26(10):1863-71.

38 Tjaden LA, Grootenhuis MA, Noordzij M, Groothoff JW. Health-related quality of life in patients with pediatric onset of end-stage renal disease: state of the art and recommendations for clinical practice. Pediatr Nephrol. 2016 Oct;31(10):1579-91.

39 Mendley SR, Matheson MB, Shinnar S, Lande MB, Gerson AC, Butler RW, et al. Duration of chronic kidney disease reduces attention and executive function in pediatric patients. Kidney Int. 2015 Apr;87(4):800-6.

40 Early Childhood Technical Assistance Center. Child Outcome Highlights FFY 2012. September 2014. Available from: http://ecta- center.org/eco/assets/pdfs/childoutcomeshighlights.pdf.

41 Chen K, Didsbury M, van Zwieten A, Howell M, Kim S, Tong A, et al. Neurocognitive and Educational Outcomes in Children and Adolescents with CKD: A Systematic Review and Meta-Analysis. Clin J Am Soc Nephrol. 2018 Mar;13(3):387-97.

42 Miller LE, Perkins KA, Dai YG, Fein DA. Comparison of parent report and direct assessment of child skills in toddlers. Res Autism Spectr Disord. 2017 Sep;41-42:57-65.

43 Sachse S, Von Suchodoletz W. Early identification of language delay by direct language assessment or parent report? J Dev Behav Pediatr. $2008 \mathrm{Feb} ; 29(1): 34-41$

44 McDonald S, Kehler H, Bayrampour H, Fraser-Lee N, Tough S. Risk and protective factors in early child development: Results from the All Our Babies (AOB) pregnancy cohort. Res Dev Disabil. 2016 Nov;58:20-30. 